\title{
Is Reactive Gliosis a Property of a Distinct Subpopulation of Astrocytes?
}

\author{
Robert H. Miller, ${ }^{*, 1}$ Erika R. Abney, ${ }^{*}$ Sam David, ${ }^{\star, 2}$ Charles ffrench-Constant, ${ }^{*}$ Ronald Lindsay, $\dagger$ \\ Ramila Patel, ${ }^{*, 3}$ Jonathan Stone, ${ }^{*, 4}$ and Martin C. Raff ${ }^{\star}$ \\ *Medical Research Council Neuroimmunology Project, Department of Zoology, University College London, London \\ WC1E 6BT, UK; and †National Institute for Medical Research, Mill Hill, London NW7 1AA, UK
}

We have shown previously that the A2B5 monoclonal antibody distinguishes two types of glial fibrillary acidic protein-containing astrocytes in semithin frozen sections of adult rat optic nerve: $\mathrm{A2B5}^{-}$(type-1) astrocytes are found mainly at the periphery of the nerve, where they form the glial limiting membrane, while $\mathrm{A2B5}^{+}$(type-2) astrocytes are found mainly in the interior of the nerve and constitute more than $65 \%$ of the astrocytes in the adult optic nerve. In the present study we show that although most astrocytes in semithin frozen sections of adult rat corpus callosum and optic nerve are $\mathrm{A2B5}^{+}$, the great majority of reactive astrocytes in similar sections of corpus callosum examined 20 weeks after a stab lesion, and in optic nerve examined 20 weeks after adult transection, are A2 B5-. Although both $\mathrm{A}^{2} \mathrm{B5}^{+}$and $\mathrm{A2B5}^{-}$astrocytes are stimulated to synthesize DNA in the first week after transection, adult optic nerves examined 20 weeks after transection contain only half as many astrocytes as do normal optic nerves: While $\mathrm{A2B5}^{+}$astrocytes are reduced almost 10-fold, $\mathrm{A}^{2} \mathrm{B5}^{-}$astrocytes are increased by about $25 \%$. We consider the simplest interpretation of these findings to be that type-1 astrocytes are largely responsible for forming glial scars in adult white matter following either a stab lesion or Wallerian degeneration and that in transected optic nerves, most type- 2 astrocytes eventually die, possibly because they depend on axons for their long-term survival.

An important property of astrocytes is that they form scar tissue in response to injury in the CNS-a process called reactive gliosis. Unlike fibroblasts, which form scars in nonneural tissues by secreting large amounts of collagenous extracellular matrix, astrocytes form scars by extending numerous processes that become packed with intracellular glial filaments (Maxwell and Kruger, 1965; Vaughn and Pease, 1970) - a special class of intermediate filaments containing glial fibrillary acidic protein (GFAP) (Bignami and Dahl, 1976; Bignami et al., 1972; Schach-

\footnotetext{
Received July 23, 1984; revised July 3, 1985; accepted July 3, 1985.

We thank Dr. M. Nirenberg for the A2B5 clone and Dr. B. Anderton for rabbit anti-NF serum. S.D. was supported by a Canadian MRC Centennial Fellowship, C.ff.-C. by the British Multiple Sclerosis Society, and R.H.M. by a fellowship from the National Fund for Research into Crippling Diseases.

Correspondence should be addressed to Martin C. Raff, Medical Research Council Neuroimmunology Project, Department of Zoology, University College London, London WC1E 6BT, United Kingdom.

Present address: Department of Anatomy, Case Western Reserve School of Medicine, Cleveland, $\mathrm{OH} 44106$.

${ }^{2}$ Present address: Division of Neurology, The Montreal General Hospital, Montreal H3G 1A4, Canada.

${ }^{3}$ Present address: Center for Cancer Research, Massachusetts Institute of Technology, Cambridge, MA 02139.

${ }^{4}$ Present address: Anatomy Department, University of New South Wales, Sydney, Australia.

Copyright $\odot 1986$ Society for Neuroscience $0270-6474 / 86 / 010022-08 \$ 02.00 / 0$
}

ner et al., 1977). Although there is now convincing evidence that astrocytes proliferate in response to injury (for example, Latov et al., 1979; Skoff, 1975), this was for some time a point of controversy (for example, Konigsmark and Sidman, 1963; Murray and Walker, 1973).

Since thure is increasing evidence that astrocytes are a heterogeneous class of cells (Miller and Raff, 1984; Peters et al., 1976; Raff et al., 1983a; Schachner, 1982), it is important to know whether all astrocytes can form glial scars or whether scar formation is a property of a specialized subclass of astrocyte. For example, we have recently shown that cell cultures of developing rat optic nerve contain two types of $\mathrm{GFAP}^{+}$astrocytes (Raff et al., 1983b): Most type-1 astrocytes have a fibroblastlike morphology and do not bind tetanus toxin or the A2B5 monoclonal antibody (Eisenbarth et al., 1979)-both of which bind specific gangliosides (Eisenbarth, 1979; Van Heyningen, 1963) - whereas most type-2 astrocytes have a process-bearing morphology and bind both tetanus toxin and A2B5 antibody. In semithin frozen sections of adult rat optic nerve, A2B5- (type1) astrocytes are found mainly at the periphery of the nerve, where they form the glial limiting membrane, while A2B5+ (type2) astrocytes constitute the great majority of the astrocytes in the interior of the nerve (Miller and Raff, 1984). We have provided evidence that the two types of astrocytes in rat optic nerve arise from two distinct precursor cells: Type- 1 astrocytes develop before birth from a type-1 precursor cell (Raff et al., 1984), while type- 2 astrocytes develop after the first postnatal week (Miller et al., 1985), probably from a serologically distinct, bipotential glial progenitor cell that, in culture at least, can develop either into an oligodendrocyte or a type-2 astrocyte (Raff et al., $1983 \mathrm{~b}, 1984)$. Since the majority of astrocytes in gray matter have a type- 1 phenotype, whereas the majority in white matter have a type- 2 phenotype, we have suggested that type- 1 and type- 2 astrocytes may correspond to anatomically defined protoplasmic and fibrous astrocytes, respectively (Miller and Raff, 1984; Raff et al., 1983a).

In the present study we have addressed the question of whether glial scars in white matter are formed by type- 1 or type- 2 astrocytes or both. We demonstrate that while most astrocytes in normal adult corpus callosum and optic nerve are $\mathrm{A} 2 \mathrm{~B}^{+}$, the great majority of reactive astrocytes in corpus callosum examined 20 weeks after stabbing, and in optic nerve examined 20 weeks after adult transection, are $\mathrm{A} 2 \mathrm{B5}^{-}$. In addition, we show that although both $\mathrm{A} 2 \mathrm{~B} 5^{+}$and $\mathrm{A} 2 \mathrm{~B} 5^{-}$astrocytes in optic nerve are stimulated to synthesize DNA in the first week after transection, 20 weeks after transection optic nerves contain only half as many astrocytes as do normal nerves: Whereas $\mathrm{A} 2 \mathrm{~B} 5^{+}$ astrocytes are reduced almost 10 -fold in cut nerves, $\mathrm{A} 2 \mathrm{~B} 5^{-}$astrocytes are increased by about $25 \%$. In light of these findings, 


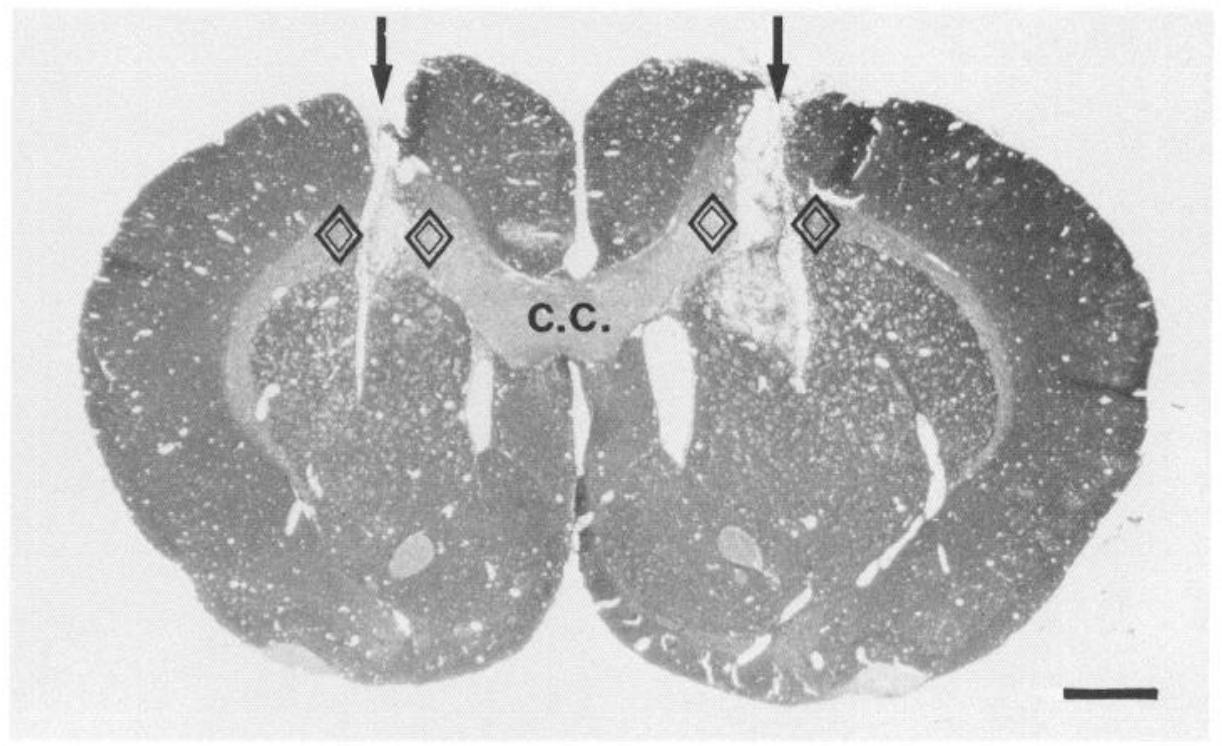

\begin{abstract}
Figure 1. Coronal section of adult rat brain at the level of the septum showing bilateral lesions (arrows) in the corpus callosum (C.C.) at $5 \mathrm{~d}$ after lesions were made (from Lindsay et al., 1982). Cell suspensions and frozen sections were taken from the areas outlined by the double diamonds. Scale bar, $1 \mathrm{~mm}$.
\end{abstract}

we hypothesize that glial scars in white matter are formed mainly by type-1 astrocytes, even though these cells constitute a minority of the astrocytes in normal white matter.

\section{Materials and Methods}

\section{Corpus callosum transection}

Young adult $(\sim 200 \mathrm{gm})$ Wistar-Furth rats were anesthetized with tribromoethanol $(0.3 \mathrm{mg} / \mathrm{gm}$ body weight, i.p.), and their heads were held in a stereotaxic apparatus. A knife, constituted from a fragment of a razor blade, was inserted vertically and stereotaxically into the brain through a dorsal craniotomy to a depth of $5.5 \mathrm{~mm}$, at the rostrocaudal level of the bregma and $2.5 \mathrm{~mm}$ lateral to the midline. The knife was then moved rostrally to the level of the frontal pole of the cerebral hemisphere. The operation, which was performed bilaterally, competely transected the fibers of the corpus callosum rostral to the bregma on each side (Fig. 1) (Lindsay et al., 1982).

\section{Optic nerve transection}

Young adult ( $\sim 200 \mathrm{gm})$ Sprague-Dawley rats were anesthetized with ether, and an incision was made behind the lateral canthus of the left eye. Blunt dissection exposed the tendon of the lateral rectus muscle, which was cut, and the sclera was followed back to the optic nerve. The eye was gently retracted, and the optic nerve was cut with microscissors just behind the globe. The incision was closed with sutures.

\section{Frozen sections}

Semithin frozen sections were prepared by a modification of the method of Tokuyasu (1973) as previously described (Miller and Raff, 1984). In brief, normal and operated rats were perfused through the ascending aorta with a combination of $3 \%$ paraformaldehyde, $0.5 \%$ glutaraldehyde, and $7 \%$ sucrose in $0.1 \mathrm{~m}$ phosphate buffer at $\mathrm{pH} 7.4$ (buffer). Optic nerves or blocks of tissue from the normal corpus callosum or walls of the lesion in corpus callosum (see Fig. 1) were removed and postfixed in the same fixative for $2-3 \mathrm{hr}$ at $4^{\circ} \mathrm{C}$ before being incubated in $2 \mathrm{M}$ sucrose in buffer for up to $3 \mathrm{hr}$. Blocks were then further trimmed to give the correct orientation, mounted onto the stub of a freezing microtome, and frozen by immersion in a slush of Freon 22, which was cooled in a bath of liquid nitrogen. Semithin frozen sections $(\sim 0.5 \mu \mathrm{m})$ were cut using a Sorvall MT 2B microtome with an FTS cryo-attachment on a $25 \mathrm{~mm}$ glass knife at $-80^{\circ} \mathrm{C}$.

\section{Immunofluorescence staining}

All of the antibodies used in these studies have been previously described. Monoclonal A2B5 antibody (Eisenbarth et al., 1979) was used as hybridoma supernatant diluted 1:2, rabbit anti-GFAP antiserum (Pruss, 1979) was diluted 1:1000, and rabbit anti-210 kDa neurofilament protein (anti-NF) (Anderton et al., 1980) was diluted 1:100. The binding of A2B5 was detected with a rhodamine-conjugated goat anti-mouse immunoglobulin (G anti-MIg-Rd; Cappel, diluted 1:100), while the binding of the rabbit antibodies was detected with a fluorescein-conjugated sheep anti-rabbit Ig (Sh anti-RIg-F1; Wellcome, diluted 1:100), which had been absorbed with mouse Ig coupled to Sepharose 4B. Cells in suspension and semithin frozen sections were double-labeled with A2B5 and either anti-GFAP or anti-NF antibodies and examined in a Zeiss Universal fluorescence microscope as previously described (Raff et al., 1983a). No significant staining was observed when normal ascites fluid or normal rabbit serum was used in place of the A2B5 or rabbit antibodies, respectively. Specimens were photographed using Tri-X film rated at 400 ASA.

\section{Autoradiography}

The left optic nerve was cut behind the eye in adult ( $\sim 350$ gm) SpragueDawley rats as described above. Three days later the rats received an intracardiac injection of $600 \mu \mathrm{Ci}$ of ${ }^{3} \mathrm{H}$-thymidine $(24 \mathrm{Ci} / \mathrm{mmol}$; Amersham), and a similar injection was given $16 \mathrm{hr}$ later. One hour after the last injection, the animals were killed and the transected optic nerves were removed. Cell suspensions were prepared with trypsin, collagenase, and EDTA as previously described (David et al., 1984), except that each of the 3 incubations was for $30 \mathrm{~min}$ rather than $20 \mathrm{~min}$. Cells were labeled in suspension with A2B5 and anti-GFAP antibodies and then allowed to settle onto poly-L-lysine (PLL)-coated glass coverslips as previously described (Raff et al., 1983a). The coverslips were coated with Ilford $\mathrm{K} 5$ emulsion, stored at $-70^{\circ} \mathrm{C}$ for 8 weeks in the dark, developed with Ilford Super Contrast FF, and finally examined as previously described (Raff et al., 1983a).

\section{Electron microscopy}

The tissues were fixed as for frozen sections except that postfixation was in $2.5 \%$ glutaraldehyde for $3-4 \mathrm{hr}$ and then in osmium tetroxide for $2 \mathrm{hr}$ followed by $0.5 \%$ aqueous uranyl acetate overnight. Following dehydration through graded alcohols and embedding in Epon 812, transverse, silver-gray sections were cut and stained with uranyl acetate and lead citrate and then examined in a Jeol 100 CXII EM at $80 \mathrm{kV}$.

\section{Results}

\section{Corpus callosum}

When semithin frozen transverse sections of adult corpus callosum were studied by indirect immunofluorescence with A2B5 and anti-GFAP antibodies, the great majority of $\mathrm{GFAP}^{+}$astrocytes were found to be A2B5+ (Fig. 2, A-C). These astrocytes had processes that ran both longitudinally and transversely and usually ended on blood vessels (Fig. 2, $A-C$ ). Many 

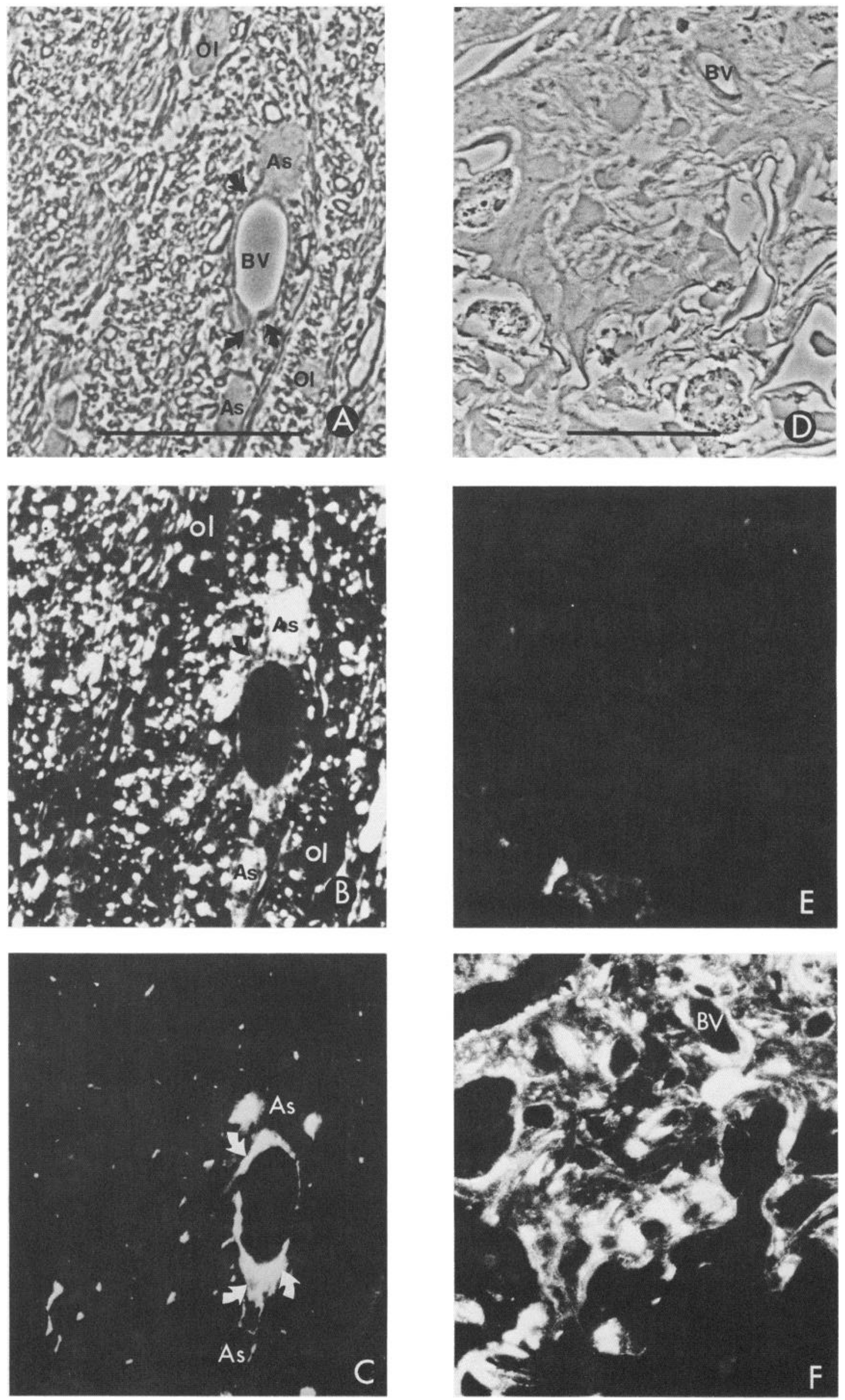
Table 1. Cell counts in semithin frozen sections of optic nerve 20 weeks after nerve transection

\begin{tabular}{llll} 
& $\begin{array}{l}\text { Glial cells/ } \\
\text { section }\end{array}$ & $\begin{array}{l}\text { A2B5 } \\
\text { GFAP } \\
\text { astrocytes }\end{array}$ & $\begin{array}{l}\text { A2B5 }^{+}, \\
\text {GFAP }^{+} \\
\text {astrocytes }\end{array}$ \\
\hline Normal nerves $^{a}$ & $331 \pm 22$ & $39 \pm 4$ & $78 \pm 10$ \\
Cut nerves & $177 \pm 14$ & $48 \pm 4.5$ & $8 \pm 0.5$
\end{tabular}

Results are expressed as means \pm SD of counts taken from 5 complete transverse sections of three different normal and two different transected optic nerves. The lengths of the normal and cut nerves were not significantly different. Sections were cut approximately midway between the eye cup and the optic chiasm; counts on sections cut just behind the eye or just anterior to the chiasm gave similar results. All cell nuclei within the boundaries of the glial limiting membrane were counted, excluding endothelial cells. Sections were labeled with A2B5 and anti-GFAP antibodies as described in text.

${ }^{a}$ Results taken from Miller et al. (1985).

$\mathrm{A}^{2} \mathrm{~B}^{-}, \mathrm{GFAP}^{-}$cells were seen; most of these were small round cells and were probably oligodendrocytes (Fig. $2, A-C$ ). In addition, A2BS ${ }^{+}$, GFAP cells were seen in some areas of the corpus callosum, but we could not be certain what type of cells these were. When the sections were labeled with A2B5 and anti-NF antibodies, all of the $\mathrm{NF}^{+}$axons were strongly $\mathrm{A}_{2} \mathrm{B5}^{+}$; no $\mathrm{NF}^{+}$ cell bodies were seen (not shown).

The brains of operated rats were examined 20 weeks after bilateral stab wounds were placed stereotaxically in the corpus callosum. When semithin, transverse frozen sections from the walls of the lesions (Fig. 1) were labeled with A2B5 and antiGFAP antibodies, the majority of cells were large, A2B5-, intensely $\mathrm{GFAP}^{+}$astrocytes (Fig. $2, D-F$ ). Only rare $\mathrm{A}_{2} \mathrm{B5}^{+}, \mathrm{GFAP}^{+}$ cells and no $\mathrm{A}_{2} \mathrm{BS}^{+}, \mathrm{GFAP}^{-}$cells were seen. There were many A2B5 ${ }^{-}$,GFAP- cells, presumably mainly oligodendrocytes and/ or microglial cells. When sections of the lesion were stained with anti-NF antibodies, no $\mathrm{NF}^{+}$axons were seen (not shown). In regions of corpus callosum well-removed from the lesion, where myelinated axons remained intact, most GFAP ${ }^{+}$astrocytes were $\mathrm{A} 2 \mathrm{B5}^{+}$and resembled astrocytes in normal corpus callosum (not shown). Astrocytes in cerebral cortex adjacent to the lesion were intensely $\mathrm{GFAP}^{+}$but A2B5- (not shown).

\section{Optic nerve}

As reported previously (Miller and Raff, 1984), when semithin transverse frozen sections of normal adult optic nerve were labeled with A2B5 and anti-GFAP antibodies, most of the $\mathrm{GFAP}^{+}$astrocytes in the interior of the nerve were A2B5', while most of the $\mathrm{GFAP}^{+}$astrocytes at the periphery of the nerve, which formed the glial limiting membrane, were A2B5- (Fig. 3, $A-C)$. Four days after transection, the picture was similar in that the majority of astrocytes were still A2B5+ (not shown). However, when cut nerves were examined 20 weeks after adult transection, there was a striking increase in GFAP staining and an equally striking decrease in A2B5 staining (Fig. 3, $D-F$ ). The increase in GFAP staining was due mainly to an increase in the number of $\mathrm{A}^{2} \mathrm{B5}^{-}, \mathrm{GFAP}^{+}$astrocyte processes, which formed a dense meshwork throughout the transected nerve (Fig. 4). The decrease in A2B5 staining was due mainly to a loss of A2B5+ axons: No $\mathrm{NF}^{+}$axons were seen in sections of cut nerves stained with anti-NF antibodies, and no myelinated axons were seen in
Table 2. ${ }^{3}$ H-thymidine autoradiography of cells dissociated from transected optic nerves

Proportion (\%)

of total cells

\begin{tabular}{|c|c|c|c|}
\hline $\begin{array}{l}\mathrm{A} 2 \mathrm{B5}^{-}, \mathrm{GFAP}^{+} \\
\text {astrocytes }\end{array}$ & 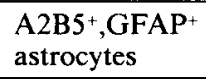 & $\begin{array}{l}{\mathrm{A} 2 \mathrm{~B}^{-}}^{-}, \mathrm{GFAP}^{+} \\
\text {astrocytes }\end{array}$ & 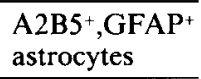 \\
\hline $5 \pm 1$ & $0.8 \pm 0.2$ & $50 \pm 11$ & $16 \pm 6$ \\
\hline
\end{tabular}

Adult rats received ${ }^{3} \mathrm{H}$-thymidine 3 and $4 \mathrm{~d}$ after their left optic nerve was cut. One hour after the last injection of ${ }^{3} \mathrm{H}$-thymidine, cells were dissociated, stained with A2B5 and anti-GFAP antibodies, and processed for autoradiography. At least 200 astrocytes of each type were counted per experiment, and astrocytes with $\geq 5$ silver grains over their nucleus were counted as radiolabeled. Results are expressed as the mean \pm SD of three separate experiments.

electron micrographs of cut nerves (Fig. 4). However, the loss of $\mathrm{A} 2 \mathrm{~B} 5$ staining was also due to a loss of $\mathrm{A}_{2} \mathrm{~B}^{+}, \mathrm{GFAP}^{+}$astrocytes: More than $85 \%$ of the GFAP $^{+}$cells were A2B5- (Table 1).

As can be seen in Table 1, the total number of glial cells per complete cross section was decreased almost twofold in nerves studied 20 weeks after transection compared with normal ones due to the loss of nonastrocytic cells as well as of $\mathrm{A} 2 \mathrm{B5}{ }^{+}$astrocytes; on the other hand, the number of A2B5- astrocytes was increased almost $25 \%$ in cut nerves. Because the outlines of individual cell nuclei were sometimes difficult to discern in semithin frozen sections of cut nerves (Fig. $3 D$ ), we counted glial cell nuclei in complete transverse thin sections of Eponembedded optic nerves in the EM. The results were within $10 \%$ of the values obtained in frozen sections: For example, in nerves cut 20 weeks previously, there were $169 \pm 12$ glial cells and $53 \pm 6$ astrocytes per complete cross section $(n=3)$, compared with $177 \pm 14$ glial cells and $56 \pm 5$ astrocytes in semithin frozen sections of similar nerves. (We reported previously that when complete semithin Epon sections of uncut nerves were stained with toluidine blue and examined by LM, the total number of glial cells was always within $10 \%$ of that obtained in semithin frozen sections.) In electron micrographs, most of the nonastrocytic cells in normal nerves were oligodendrocytes, while most of the nonastrocytic cells in cut nerves consisted of both oligodendrocytes and microglial cells, although it was often difficult to tell whether a nonastrocytic cell was an oligodendrocyte or a microglial cell (Fig. 4). Nonetheless, since the total number of nonastrocyte glial cells per cross section was decreased almost twofold in cut compared with normal nerves (Table 1), the number of oligodendrocytes must have been decreased at least twofold in cut nerves.

\section{${ }^{3} \mathrm{H}$-thymidine autoradiography of cells dissociated from transected optic nerve}

Adult rats, which had one optic nerve cut, received ${ }^{3} \mathrm{H}$-thymidine 3 and $4 \mathrm{~d}$ after the transection and were killed $1 \mathrm{hr}$ after the last injection. Cells were dissociated from the cut nerve, labeled with A2B5 and anti-GFAP antibodies, and processed for autoradiography. As can be seen in Table 2, approximately $5 \%$ of the cells were $\mathrm{GFAP}^{+}$and more than $85 \%$ of these were $\mathrm{A}_{2} \mathrm{~B}^{-}$; about $50 \%$ of the $\mathrm{A} 2 \mathrm{B5}^{-}, \mathrm{GFAP}^{+}$astrocytes and about $15 \%$ of the $\mathrm{A}_{2} \mathrm{~B} 5^{+}, \mathrm{GFAP}^{+}$astrocytes were radiolabeled.

Figure 2. Transverse semithin frozen sections of normal $(A-C)$ and lesioned $(D-F)$ adult corpus callosum labeled with A2B5 antibody followed by $\mathrm{G}$ anti-MIg-Rd and then anti-GFAP antiserum followed by Sh anti-RIg-F1. $A$ and $D$, Phase contrast; $B$ and $E$, rhodamine labeling with A2B5; $C$ and $F$, fluorescein labeling with anti-GFAP. Note that in the normal nerve, only the astrocyte processes are GFAP+ (arrows), while the astrocyte cell bodies $(A s)$ and processes, as well as the axons, are A2B5 ${ }^{+}$. The putative oligodendrocytes $(o l)$ and myelin sheaths are not labeled by either antibody. $B V$ indicates a blood vessel. In the lesioned corpus callosum, examined 20 weeks after lesioning, the overall architecture is dramatically altered. No myelinated axons are seen, and much of the tissue consists of A2B5-,GFAP ${ }^{+}$astrocytes and their processes. Note the virtual absence of A2B5 staining. Scale bars, $30 \mu \mathrm{m}$. 

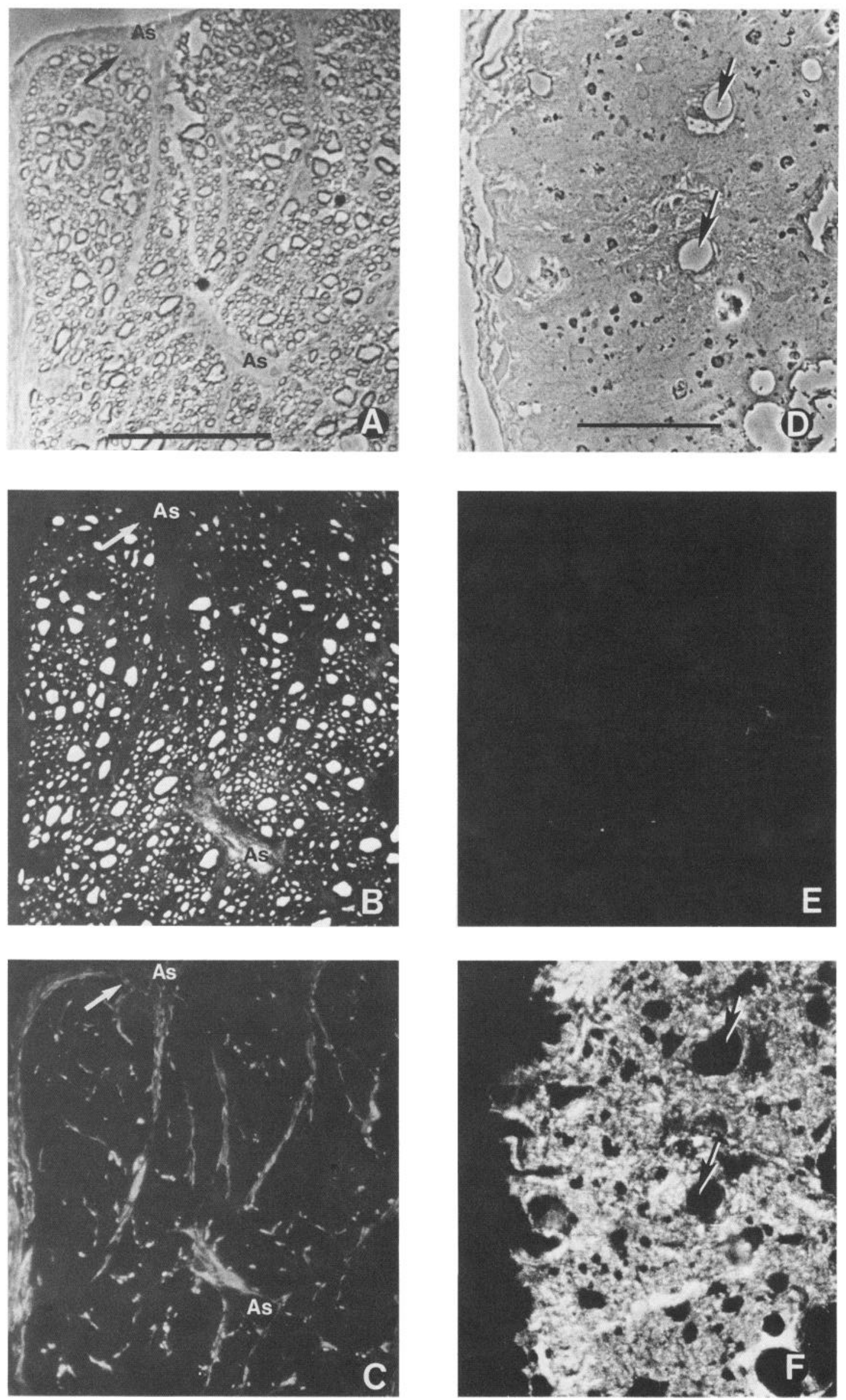


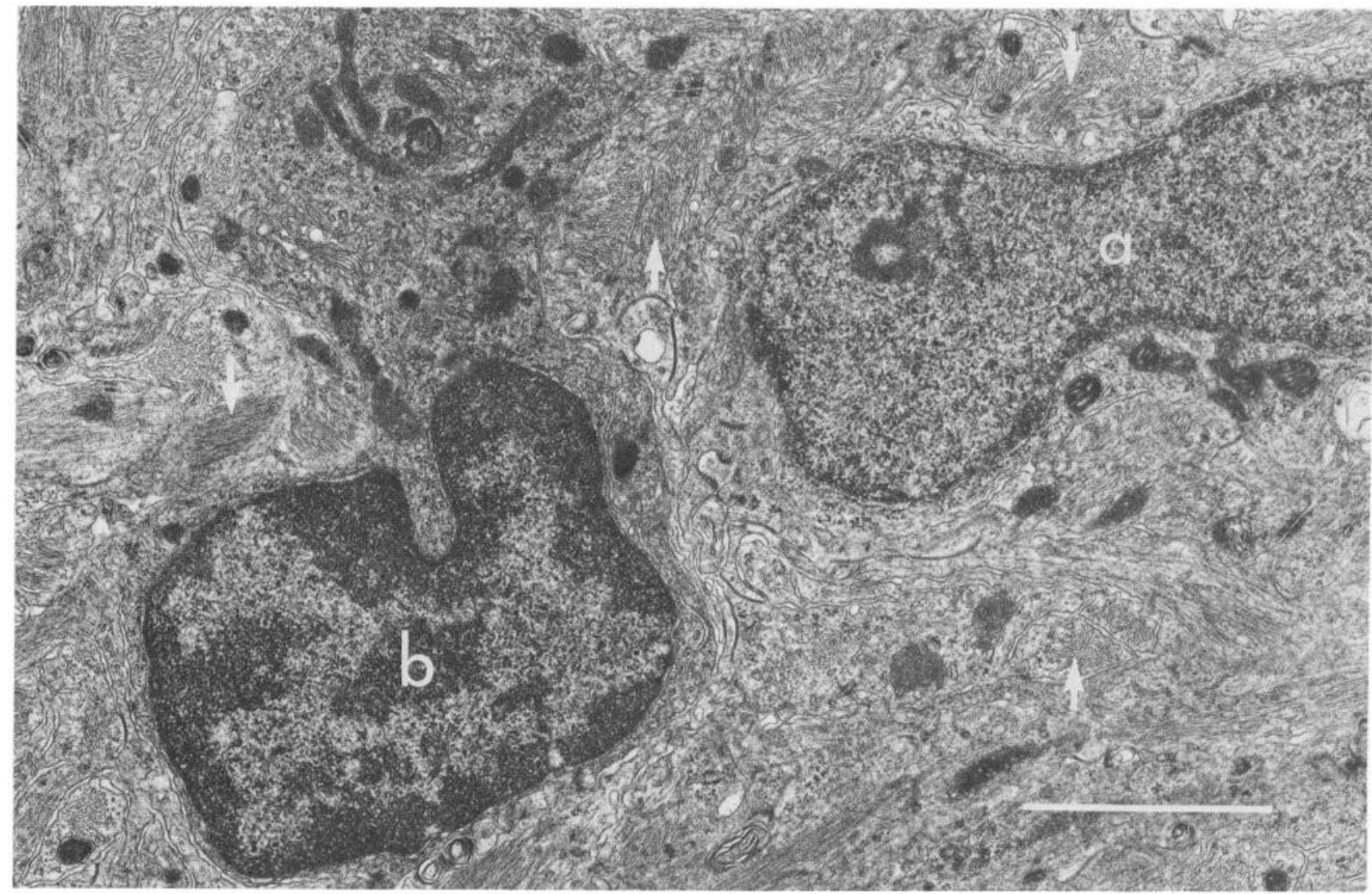

Figure 4. Electron micrograph of transverse section through a cut optic nerve examined 20 weeks after transection. Two cell bodies are seen embedded in a dense meshwork of astrocyte processes containing large bundles of glial filaments (arrows). The cell on the right (a) is clearly an astrocyte, while the cell on the left $(b)$ is probably an oligodendrocyte. Note the absence of axons. Scale bar, $2.5 \mu \mathrm{m}$.

\section{Discussion}

We found previously that the majority of $\mathrm{GFAP}^{+}$astrocytes dissociated from adult rat corpus callosum 5 or $8 \mathrm{~d}$ following a stab lesion did not bind tetanus toxin or A2B5 antibody and thus had the characteristics of type-1 rather than type- 2 astrocytes (Raff et al., 1983a). This was surprising, since the majority of astrocytes in mature white matter are $\mathrm{A} 2 \mathrm{~B} 5^{+}$type- 2 astrocytes, as shown previously in the rat optic nerve (Miller and Raff, 1984) and demonstrated here for the corpus callosum. In the present study we found that more than $85 \%$ of the GFAP ${ }^{+}$ astrocytes in cell suspensions prepared from adult optic nerves transected 4 d previously were A2B5- ${ }^{-}$. However, when semithin frozen sections of optic nerve were examined $4 \mathrm{~d}$ after transection, most of the $\mathrm{GFAP}^{+}$astrocytes in the nerve were $\mathrm{A}_{2} \mathrm{B5}^{+}$, just as in the uncut control nerves. It seems that the type-1 astrocytes are more readily released from recently cut optic nerves than are type- 2 astrocytes, and it seems likely that this is also the case in recently lesioned corpus callosum. More than 20fold fewer viable astrocytes are released by our dissociation procedures from normal adult corpus callosum (Lindsay et al., 1982) or optic nerve (unpublished observations) than from these tissues in the first week or two after lesioning. Therefore, one possible explanation for the finding that many more A2B5astrocytes than $\mathrm{A} 2 \mathrm{~B}^{+}$astrocytes can be released from acute white matter lesions is that reactive astrocytes are released more readily than nonreactive ones and that most of the reactive astrocytes in such circumstances are type-1 astrocytes.

The results of ${ }^{3} \mathrm{H}$-thymidine autoradiographic studies were consistent with this possibility. Whereas we found that both $\mathrm{A}_{2} \mathrm{~B}^{+}{ }^{+}$and $\mathrm{A} 2 \mathrm{~B}^{-}{ }^{-}$astrocytes in cut optic nerves were stimulated to synthesize DNA in the first week following transection, the proportion of $\mathrm{A}^{2} \mathrm{B5}^{-}$astrocytes that were so stimulated was more than $3 \times$ greater than that of $\mathrm{A} 2 \mathrm{~B} 5^{+}$astrocytes.

Further evidence that type-1 astrocytes may play a dominant role in reactive gliosis in white matter comes from our finding that the great majority of reactive astrocytes in semithin frozen sections of adult corpus callosum and optic nerve were A2B5 when these tissues were studied 20 weeks after lesioning. Moreover, despite the fact that both $\mathrm{A} 2 \mathrm{~B} 5^{+}$and $\mathrm{A} 2 \mathrm{~B} 5^{-}$astrocytes were stimulated to synthesize DNA (and presumably to proliferate) following optic nerve transection, the total number of astrocytes per complete cross section in optic nerves examined 20 weeks after transection had decreased almost twofold: While the number of A2B5- astrocytes increased by almost $25 \%$, the number of $\mathrm{A}_{2} \mathrm{~B} 5^{+}$astrocytes decreased almost 10 -fold. The number of oligodendrocytes also decreased at least twofold in cut nerves. These results are consistent with the findings of Fulcrand and Privat (1977), who demonstrated a progressive loss of oligodendrocytes in rat optic nerves cut at $20 \mathrm{~d}$ of age,

Figure 3. Transverse semithin frozen sections of normal $(A-C)$ and transected $(D-F)$ optic nerve labeled and viewed as in Fig. 2. Note that in the normal nerve the astrocyte $(A s)$ at the pial surface (arrow) is A2B5-, while the astrocyte $(A s)$ in the interior of the nerve is A2B5+; in addition, all of the axons are $\mathrm{A} 2 \mathrm{~B} 5^{+}$. The astrocyte processes forming the glial limiting membrane on the left of the section are A2B5-. In the cut nerve, GFAP staining is greatly increased, but there is no A2B5 staining. Arrows indicate blood vessels in the cut nerve. Scale bars, $30 \mu \mathrm{m}$. 
but they are inconsistent with the findings of Vaughn et al. (1970), who reported that the numbers of oligodendrocytes (and astrocytes) in optic nerve remained relatively unchanged for $250 \mathrm{~d}$ following eye enucleation in young adult rats. To our knowledge, the present study provides the first evidence that many astrocytes die in the process of Wallerian degeneration in CNS white matter.

In a previous study, designed to examine the influence of axons on glial cell development, we found that neonatal optic nerve transection in rats resulted in a striking decrease in the numbers of oligodendrocytes and type- 2 astrocytes that developed but had much less influence on the number of type-1 astrocytes, whose processes eventually occupied most of the cut nerve (David et al., 1984). Although the numbers of putative oligodendrocyte-type-2 astrocyte progenitor cells were greatly decreased in neonatally transected nerves, the proportion of such cells that incorporated ${ }^{3} \mathrm{H}$-thymidine into DNA was not (David et al., 1984). On the basis of these results, we hypothesized that neonatal transection of the optic nerve resulted in large-scale death of oligodendrocyte-type-2 astrocyte progenitor cells and/or their progeny and that the survival of this cell lineage depends on the presence of intact axons in the nerve, at least during postnatal development. Our present results, and those of Fulcrand and Privat (1977), suggest that type-2 astrocytes and oligodendrocytes, but not type- 1 astrocytes, may depend on axons throughout life for their long-term survival.

The simplest interpretation of our present findings is that type- 1 astrocytes are largely responsible for forming glial scars in adult white matter tracts following either a stab wound or Wallerian degeneration, while most type- 2 astrocytes (and oligodendrocytes) eventually die, possibly because they depend on axons for their long-term survival. An alternative interpretation is that type- 2 astrocytes make a major contribution to the formation of glial scars in white matter, but become A2B5- in doing so. Although we cannot exclude the latter possibility, we think it is unlikely for the following reason. The twofold decrease in total astrocyte numbers seen 20 weeks after adult optic nerve transection cannot be explained by a simple conversion of type2 to type-1 astrocytes, especially in view of our evidence that both type- 1 and type- 2 astrocytes proliferate during the first week after transection. On the other hand, it could be explained by a large-scale loss of type- 2 astrocytes that is incompletely compensated for by the proliferation of type- 1 astrocytes.

Our findings illustrate some difficulties with current astrocyte nomenclature. Anatomists traditionally distinguish between fibrous astrocytes, which have many glial filaments and are located mainly in white matter, and protoplasmic astrocytes, which have fewer glial filaments and are located mainly in gray matter (Peters et al., 1976). Since the astrocytes forming glial scars are packed with glial filaments, they are often referred to as fibrous astrocytes (for example, Vaughn and Pease, 1970), although it has been unclear whether they derive from protoplasmic astrocytes, fibrous astrocytes, or both. We originally adopted a numeric terminology to distinguish the two classes of astrocytes found in cultures of optic nerve and other regions of CNS (Raff et al., 1983a). Since almost all of the astrocytes in cultures of gray matter were phenotypically type-1, while a large proportion of the astrocytes in cultures of white matter were phenotypically type-2, we suspected that type- 1 and type- 2 astrocytes in vitro corresponded to protoplasmic and fibrous astrocytes, respectively, in vivo (Rafl et al., 1983a). This was largely confirmed by two-fluorochrome immunofluorescence studies using A2B5 and anti-GFAP antibodies on semithin frozen sections of adult optic nerve and cerebral cortex (Miller and Raff, 1984). However, we feel there are good reasons for abandoning the fibrousprotoplasmic terminology. In some circumstances, type-1 astrocytes contain large numbers of glial filaments - for example, in cell culture (unpublished observations) and in response to injury in vivo (Bignami and Dahl, 1976). Even in normal adult optic nerve, type- 1 and type- 2 astrocytes are not morphologically distinguishable and have both generally been considered to be fibrous astrocytes because they are located in a purely white matter tract. Since type-1 and type- 2 astrocytes differ in so many other properties (Raff and Miller, 1984), it seems illogical to continue to single out an inconsistent morphological difference as a basis for naming them. Moreover, as it is likely that there are many more subclasses of astrocytes still to be discovered (for example, see Schachner, 1982), a numeric classification may help to avoid confusion in the future. Ultimately, one would like to distinguish astrocyte subclasses according to their different functions. Since one of the few established functions of astrocytes in the adult mammalian CNS is the formation of glial scars, it is gratifying that type- 1 and type- 2 astrocytes seem to differ in this respect.

\section{References}

Anderton, B. H., R. Thorpe, J. Cohen, S. Selvendran, and P. Woodhams (1980) Specific neuronal localization by immunofluorescence of 10 nm filament polypeptides. J. Neurocytol. 9: 835-844.

Bignami, A., and D. Dahl (1976) The astroglial response to stabbing. Immunofluorcscence studics with antibodics to astrocyte-specific protein (GFA) in mammalian and submammalian vertebrates. Neuropathol. Appl. Neurobiol. 2: 99-110.

Bignami, A., L. F. Eng, D. Dahl, and C. T. Uyeda (1972) Localization of the glial fibrillary acidic protein in astrocytes by immunofluorescence. Brain Res. 43: 429-435.

David, S., R. H. Miller, R. Patel, and M. C. Raff (1984) Effects of neonatal transection on glial cell development in the rat optic nerve: Evidence that the oligodendrocyte-type- 2 astrocyte cell lineage depends on axons for its survival. J. Neurocytol. 13: 961-974.

Eisenbarth, G. S., F. S. Walsh, and M. Nirenberg (1979) Monoclonal antibody to a plasma membrane antigen of neurons. Proc. Natl. Acad. Sci. USA 76: 4913-4917.

Fulcrand, J., and A. Privat (1977) Neuroglial reactions secondary to Wallerian degeneration in the optic ncrve of the postnatal rat: Ultrastructural and quantitative study. J. Comp. Neurol. 176: 189-224.

Konigsmark, B. W., and R. L. Sidman (1963) Origin of brain macrophages in the mouse. J. Neuropathol. Exp. Neurol. 22: 643-676.

Latov, N., N. Gajanan, E. A. Zimmerman, W. G. Johnson, A. Silverman, R. Defendini, and L. Cote (1979) Fibrillary astrocytes proliferate in response to brain injury. A study combining immunoperoxidase technique for glial fibrillary acidic protein and radiography of tritiated thymidine. Dev. Biol. 72: 381-384.

Lindsay, R. M., P. C. Barber, M. R. C. Sherwood, J. Zimmer, and G. Raisman (1982) Astrocyte cultures from adult rat brain. Derivation, characterization and neurotrophic properties of pure astroglial cells from corpus callosum. Brain Res. 243: 329-343.

Maxwell, D. S., and L. Kruger (1965) The fine structure of astrocytes in the cerebral cortex and their response to focal injury produced by heavy ionizing particles. J. Cell Biol. 25: 141-157.

Miller, R. H., and M. C. Raff (1984) Fibrous and protoplasmic astrocytes are biochemically and developmentally distinct. J. Neurosci. 4: 585-592.

Miller, R. H., S. David, R. Patel, E. R. Abney, and M. C. Raff (1985) A quantitative immunohistochemical study of macroglial cell development in the rat optic nerve: In vivo evidence for two distinct astrocyte lineages. Dev. Biol. 111: 35-41.

Murray, H. M., and B. E. Walker (1973) Comparative study of astrocytes and mononuclear leukocytes reacting to brain trauma in mice. Exp. Neurol. 41: 290-302.

Peters, A., S. L. Palay, and H. deF. Webster (1976) The Fine Structure of the Nervous System: The Neurons and Supporting Cells, pp. 233244, Saunders, Philadclphia.

Pruss, R. (1979) Thy-1 antigen on astrocytes in long-term cultures of rat central nervous system. Nature 280: 688-690.

Raff, M. C., and R. H. Miller (1984) Glial cell development in the rat optic nerve. Trends Neurosci. 7: 469-472.

Raff, M. C., E. R. Abney, J. Cohen, R. Lindsay, and M. Noble (1983a) Two types of astrocytes in cultures of developing rat white matter: Differences in morphology, surface gangliosides and growth characteristics. J. Neurosci. 3: 1289-1300. 
Raff, M. C., R. H. Miller, and M. Noble (1983b) A glial progenitor cell that develops in vitro into an astrocyte or an oligodendrocyte depending on the culture medium. Nature 303: 390-396.

Raff, M. C., E. R. Abney, and R. H. Miller (1984) Two glial cell lineages diverge prenatally in rat optic nerve. Dev. Biol. 106: 53-60.

Schachner, M. (1982) Immunological analysis of cellular heterogeneity in the cerebellum. In Neuroimmunology, J. Brockes, ed., pp. 215250, Plenum, New York.

Schachner, M., E. T. Hedley-White, D. W. Hsu, G. Schoonmaker, and A. Bignami (1977) Ultrastructural localization of glial fibrillary acidic protein in mouse cerebellum by immuno-peroxidase labelling. $J$. Cell Biol. 75: 67-73.

Skoff, R. P. (1975) The fine structure of pulse labelled ( ${ }^{3} \mathrm{H}$-thymidine) cells in degenerating rat optic nerve. J. Comp. Neurol. 161: 595-612.
Tokuyasu, K. T. (1973) A technique for ultracryotomy of cell suspensions and tissues. J. Cell Biol. 37: 551-565.

Van Heyningen, W.E. (1963) The fixation of tetanus toxin, strychnine, serotonin and other substances by gangliosides. J. Gen. Microbiol. 31: 375-387.

Vaughn, J. E., and D. C. Pease (1970) Electron microscopic studies of Wallerian degeneration in rat optic nerves. II. Astrocytes, oligodendrocytes and adventitial cells. J. Comp. Neurol. 140: 207-226.

Vaughn, J. E., P. L. Hinds, and R. P. Skoff (1970) Electron microscopic studies of Wallerian degeneration in rat optic nerves. $I$. The multipotential glia. J. Comp. Neurol. 140: 175-206. 